\title{
An Evaluation of the Assessment Process used in an Education Development Programme: A Case Study of the Advanced Certificate in Education (ACE) Project in Bloemfontein in South Africa
}

\author{
Dr Joseph Ramathibela Maimane \\ School of Teacher Education, Faculty of Humanities, Central University of Technology, Free State, \\ Private Bag X20539, Bloemfontein 9300, South Africa \\ Email:jmaimane@cut.ac.za
}

\section{Doi:10.5901/mjss.2014.v5n27p1397}

\section{Abstract}

The study aims to evaluate the performance of educators who participated in the Advanced Certificate in Education (ACE) project provided by the Motheo District and the assessment procedure employed to assess the competency of the participants. The participants were from two districts of the Free State Province, namely: Thabo Mofutsanyana (Qwa Qwa) and Lejweleputswa (Odendaalsrus). Twenty seven (15 females and 12 males) were from Odendaalsrus and twenty five (14 females and 11 males) were from Qwa-Qwa. Qualitative and quantitative data were collected in this study. Quantitative interpretation of data was done using Microsoft Excel 2000 to map-out and display data. The questions were analyzed using Gowin's epistemology $V$ and Bloom's Taxonomy. Through the use of assessing the examination question papers that the facilitators set for the educators and interviews with the participants it was evident that the manner in which assessment was conducted did not conform to the principles of setting a question paper that is questions asked should not be too easy or too difficult. They should be real examination questions covering all the competences of the students.

Keywords: Bloom's taxonomy, cognitive domain, epistemology

\section{Introduction}

Since the democratically elected South African government came into being in 1994, and the new education approach was introduced, that is, Outcomes-based Education (OBE), researchers focused with great interest on whether the learners and teachers will cope with the numerous problems the new approach posed with regards to teacher competence (Gultig \& Stielau eds (2009:3), how to implement a child- centred system (Hoadley \& Jansen 2009: 159), resources (Fullan 1994 as cited in Aldridge, Fraser \& Sebela 2004: 245), problems with the implementation of continuous assessment (Ramsuran 1999:99). The Department of Education did not ignore the criticisms of those who were concerned with the new educations dispensation. Teachers' workshops were held in all the provinces with the sole aim of helping them with the implementing of the new curriculum. In its endeavour to effect changes and improve the development of the educators, Motheo District authorities discovered that variables such as content, knowledge, qualifications, communication, commitment and lack of skills seem to impact heavily on the performance of educators.

\section{Context of the Study}

The Motheo District Project is grounded from the concerns expressed by the Department of Education (DoE) in 1996, that: "Natural Sciences and Mathematical Sciences are critical for South Africa's social and economic development, yet there are areas in which our human resources are sorely lacking" (Department of Education 1996). The enrolment for the subjects Mathematics and Physical Sciences of the final year school population that time were below twenty percent and the pass rate for these subjects in terms of the learners who eventually wrote the examination were below fifty percent.

In its endeavour to effect changes and improve the mathematical competence of educators, Motheo District authorities discovered that variables such as the learning content, knowledge, qualifications communication, commitment and lack of skills seem to impact heavily on the performance of educators. The yearning for quality education- specifically in mathematics is an insatiable desire of every community that needs to compete on equal basis with other progressive countries in the world. As an important aspect of human development, education is said to be more than reading, writing and arithmetic. The argument is that it should address important aspects such as relevance, universal values, peace and 
security and informed decision-making and it has to be evaluated in order to ascertain if it is on the same level or standard with education systems of other countries.

\section{Research Question}

The following research question guided the study:

What assessment competencies should students doing Advanced Certificate in Education (ACE) have in drawing conclusions from the results obtained during the evaluated mathematics examination scripts?

\section{Method}

To achieve the objectives of this study of the Motheo District project, one of the following procedures can be attempted: (a) Observe the students as they participate during the facilitation of the module; and (b) Analyse their question paper and marked scripts after the module examination. The second option was used. The following question was asked: Since the objectives or operational efficiency of the project will depend on their degree of understanding certain concepts and performing given task, did the educational development project produce competent and knowledgeable mathematics teachers?

\subsection{Data collection}

Primary as well as secondary sources were used to collect qualitative data. The primary sources were the examination question paper written at the end of the semester, the examination scripts of the students and the continuous assessment marks of the students. Secondary sources were books on the subject under discussion. Also information was gathered by personal observations and discussions with some of the lecturers presenting the course and students doing advance education programme..

\subsection{Participants and setting}

The sample used consisted of participants on the ACE programme, for purposes of analyzing the module assessment question paper and the scripts of 52 project participants were used. All the participants were senior phase mathematics educators at their schools who were awarded bursaries by the Department of Education (DoE) to improve their qualifications in mathematics, by attending the Motheo District ACE programme. The participants were from two districts of the Free State Province, namely: Thabo Mofutsanyana (Qwa Qwa) and Lejweleputswa (Odendaalsrus). Twenty seven (15 females and 12 males) were from Odendaalsrus and twenty five (14 females and 11 males) were from Qwa-Qwa. Ethical considerations such as autonomy- which infers that the participant has the right to freely decide to participate in the research without fear of feeling that he/she has been forced and with a full understanding of what is being researched. Non-maleficence- this implies an intention of not harming but ensuring that harm is not occurring to any participant during research. Beneficence- implies that everyone is to gain by the finding of the research whether being individuals or the community as a whole. Justice- on the other hand is concerned with participants being treated as equals irrespective of the groups or areas they come from (Coughlan et al, 2007). Issues of anonymity and respect for the property of others were crucial so that legal measures were not to be experienced. Permission was also sort from the faculty in order to do research.

\subsection{Data analysis}

Qualitative and quantitative data were collected in this study. Quantitative interpretation of data was done using Microsoft Excel 2000 to map-out and display data. Quantitative measurements according to Bless \& Higson- Smith are useful because they help in determining: Firstly whether there is "magnitude, which is the ability to compare different quantities or intensities so as to assess whether two values or levels of a variable are the same, or one is lesser or greater than the other. Secondly, whether "the existence of equal intervals, which allow magnitude to be expressed by a certain number units on a scale, all the scale being equal by definition and Lastly: "the existence of an absolute zero, which is a value indicating that the measurement of a variable is meaningless in circumstances in which the variable is non-existent" (1995:100). 
Initially the examination question paper was analyzed to determine the levels of the cognitive domain in which the questions were asked. Triangulation process was undertaken by comparing the results with those of the students who are doing the same course with the School of Education, to ascertain validity because exercises and examination questions may be set without taking their purpose into consideration. The performances of the participants were analyzed by examining their marked scripts. The names of the learners on the scripts were covered so as to avoid knowing who the owner was. The researcher had a briefing session with the educators before marking the scripts with regard to ethical issues regarding fairness, frankness, and integrity. They were not to reveal the names of the schools and educators who marked the scripts.

\section{Results and Findings}

\subsection{The Examination Question Paper}

The questions were analyzed using Gowin's epistemology $V$ and Bloom's Taxonomy. The following criteria received attention: Content and knowledge: It is important to know the depth of content and knowledge of the candidates in order to ensure that what was imparted to them had been understood.

Synthesis of knowledge gained: the ability to synthesis the knowledge acquired is very important and the educator has to determine whether learners are able to do that.

Interpretation of the questions: Having synthesized the knowledge provided, it is of outmost importance that an evaluation of some sort has to be done to determine if the student is competent to make sense out of the knowledge presented. In this case the teacher should formulate questions in such a manner that a student's ability is enhanced to the optimum and that he/she should realize the value of what has been learned.

With this in mind, the composition of the question paper was analysed in order to determine whether it aimed at eliciting the potential of the educators with regards to what they learnt during the first semester of their participation in the programme. The manner in which the questions were formulated was crucial to the study. The domain around which the questions were constructed would suggest a certain required performance levels in relation to the content and knowledge base of the students.

\subsubsection{Composition of the Examination Paper}

The examination paper was constructed using the framework of Bloom's Taxonomy. It was not clustered with jargons that would confuse the students. The following were observed from a scrutiny of the examination paper.

There were 4 questions based on the cognitive domain, with the total marks of 50. The duration of the examination was one hour.

Question 1 subsections a, c and e, were based on use knowledge, asking the respondent to recall facts, e.g.,

1 (a) Define what a prime number is and give an example.

1(c) Define what a factor is and give an example

$1(\mathrm{e})$ Define an improper fraction and give an example

The above questions can also be classified as being the ingredients of reception learning in Gowin's epistemological V. What the student has to do is to regurgitate the information he/she has learned about mathematical concepts. He/She does not have to look for answers outside of what he/she has memorized. This resonates well with the first level of the cognitive domain of Bloom because here the student has to recall what has been memorized.

Question 1(b) was based on the fourth level of cognitive domain (analysis: breaking material down into elements and detecting relationships), e.g.,

'Differentiate between the concepts: square and square root.' (Use examples).

Question 1(d) was a third level question that called for application (using abstract knowledge in specific situations), e.g.,

'When dividing a number by another number, the answer is always smaller. Discuss to whether you agree or not. Illustrate with an example.'

This question calls on the thinking (left side) and the doing activities (right side) of the epistemological $V$ because the student is virtually supposed to use abstract knowledge (Bloom's Taxonomy) in a specific situation.

Question 2 fell in the second level of the cognitive domain (Comprehension), e.g.,

'Determine the (1) first nine multiples (2) first two common multiple of the numbers and write it as a set.' 
Question 3 was also a comprehension type of question, e.g.,

$2(-9)(-2)=$

These questions basically determine whether the knowledge or concepts had been truly grasped by the learner and he/she can use them in any situation. Such a question is related to the Gowin's epistemological $V$ with relation to the mastery of concepts and the ability to generalize or explain. It belongs to the second level of Bloom's Taxonomy.

Question 4 was a mixture of comprehension and application, e.g.

Comprehension:

$3 / 4$

$2 / 3$

$3+2=$

$1 / 4$

$1 / 2$

$2 / 3$

$1 /(1+1)=$

Application:

There are 420 learners in grade $4-9$ at a certain school. $55 \%$ of the learners are in the intermediate phase. How many learners are in the senior phase?

The second and third levels of Bloom's cognitive domain characterize this question. In the third level the student is expected to be able to demonstrate that he/she has the ability to solve problems. With regard to Gowin's $\mathrm{V}$, the question can be regarded as the one that will determine the learning efficiency of the student in terms of the concepts mastered.

\subsection{Learner Performance}

After a scrutiny of the examination question paper, an inspection of the scripts of the students was undertaken. The marks obtained per questions were analysed using the Excel program.

The first procedure was to capture all the marks of the students without taking into consideration the district from which they came. This was done to find out the overall performance. Thereafter the marks of the respondents separated according to the centres from which they came. The reason for this was to determine which of the two groups was performing better than the other. The percentage obtained in each of the questions was calculated as well as the standard deviation in order to determine the spread of the marks.

After the computation of data the attempt was made to explain errors that were made when answering the questions. The emphasis fell on those questions in which respondents performed rather poorly. A rubric was designed to grade the answers. It ranged from level 0 to 6 . The levels tell us about the success of the problem solving effort by the student and how it could be improved.

\subsection{Results of the Study}

The results of the study of the learner performance are analysed below.

Table 1: Results of the numeracy participants in the ACE programme

\section{Odendaalsrus and Qwa Qwa: 2002}

\begin{tabular}{|c|c|c|c|c|c|c|c|c|c|c|c|c|}
\hline Questions & $1 \mathrm{a}$ & $1 \mathrm{~b}$ & $1 \mathrm{c}$ & $1 \mathrm{~d}$ & $1 \mathrm{e}$ & 2 & 3 & $4 \mathrm{a}$ & $4 \mathrm{~b}$ & $4 \mathrm{c}$ & $4 \mathrm{~d}$ & $\%$ \\
\hline Std Dev & 0.81 & 0.67 & 0.65 & 0.676 & 0.54 & 3.54 & 2.22 & 0.9 & 0.81 & 1.24 & 1.21 & 16.4 \\
\hline Average & 1.4 & 1.5 & 1.7 & 0.4 & 1.8 & 7.6 & 7.3 & 4.6 & 3.5 & 5.4 & 4.2 & 78.7 \\
\hline$\%$ & 68.8 & 74.5 & 84.3 & 19.6 & 89.2 & 76.1 & 72.5 & 91.8 & 88.2 & 90.5 & 84.7 & 78.7 \\
\hline
\end{tabular}

Table 1 presents the results for all the participants, that is, the mathematics educators from Thaba Mofutsanyana (Qwa Qwa) and Lejweleputsa (Odendaalsrus). The overall percentage attained for all the questions was $78.7 \%$ with a standard deviation of 16.37. The results indicate that most of the participants managed to do exceptionally well in question 4(a) obtaining an average percentage mark of $91.8 \%$. In contrast to this, the worst performance by the participants was in question 1 (d). The average percentage mark for question 1 (d) was 19.6\%. Almost all the participants from Odendaalsrus got zero. Actually, only one participant managed to get two marks for this question. What it indicates is that there might 
be some discrepancies in the marking of the question or that the participants did not do what was expected of them. Results for this question are much lower than those obtained in any other questions comparatively speaking.

To give the reader a better understanding of the results of the students, the results were separated according to their respective delivery areas. It helps in the clarification of the poor performance of students in question 1 (d) and tells us which group of students underperformed.

Table 2: Results of the numeracy participants in the ACE program (Qwaqwa)

\begin{tabular}{|c|c|c|c|c|c|c|c|c|c|c|c|c|}
\hline Questions & $1 \mathrm{a}$ & $1 \mathrm{~b}$ & $1 \mathrm{c}$ & $1 \mathrm{~d}$ & $1 \mathrm{e}$ & 2 & 3 & $4 \mathrm{a}$ & $4 \mathrm{~b}$ & $4 \mathrm{c}$ & $4 \mathrm{~d}$ & $\%$ \\
\hline Std Dev & 0.14 & 0.58 & 0.37 & 0.72 & 0.47 & 3.75 & 2.17 & 1.00 & 0.82 & 1.59 & 1.25 & 16.76 \\
\hline Average & 1.80 & 1.56 & 1.84 & 0.76 & 1.84 & 7.08 & 7.28 & 4.56 & 3.56 & 5.12 & 4.32 & 79.44 \\
\hline$\%$ & 90.0 & 78.0 & 92.0 & 38.0 & 92.0 & 70.8 & 72.8 & 91.2 & 89.0 & 85.3 & 86.4 & 79.4 \\
\hline
\end{tabular}

The results in Table 2 illustrated that the Qwaqwa participants performed well in all the questions except $1(\mathrm{~d})$ where the average mark was 38\%. Although students performed exceptionally well, overall it can be observed that in question 2 and 3 , the average mark was $71.8 \%$ with $70.8 \%$ for question 2 and $72.8 \%$ for question 3.

Table 3: Percentage of the numeracy in the ACE program (Odendaalsrus)

\begin{tabular}{|c|c|c|c|c|c|c|c|c|c|c|c|c|}
\hline Questions & $1 \mathrm{a}$ & $1 \mathrm{~b}$ & $1 \mathrm{c}$ & $1 \mathrm{~d}$ & $1 \mathrm{e}$ & 2 & 3 & $4 \mathrm{a}$ & $4 \mathrm{~b}$ & $4 \mathrm{c}$ & $4 \mathrm{~d}$ & Mark (\%) \\
\hline Std Dev & 0.9 & 0.8 & 0.8 & 0.4 & 0.6 & 3.6 & 2.3 & 0.8 & 0.8 & 0.7 & 1.2 & 16.1 \\
\hline Average & 1 & 1.4 & 1.6 & 0.1 & 1.7 & 7.8 & 7.2 & 4.6 & 3.5 & 5.7 & 4.2 & 77.6 \\
\hline$\%$ & 49.1 & 72.2 & 77.8 & 3.7 & 87 & 78.1 & 72.2 & 91.9 & 88 & 94.4 & 83.7 & 77.6 \\
\hline
\end{tabular}

From Table 3, it can be observed that the Odendaalsrus participants did not do well in questions 1(a) (49.1\%) and 1(d) was the worst with $3.7 \%$, which could have been caused by various reasons such as: misunderstanding of the question, inconsistence in marking the scripts because two people are involved in the marking or no memorandum was used in marking the scripts. With regards to questions 1 (b) and 1 (c) and 1 (a) the performance was quite good with the percentage above $70 \%$. The respondents performed very well in question 4 as a whole with the percentage marks of $80 \%$ which is consistent with the general results of Table 1. This high score indicate that most of the educators were able to perform above the standard set for the examination paper.

\section{Findings}

In analysing the examination paper it was observed that the questions focused mainly on the lower levels of the cognitive domain, i.e., knowledge and comprehension levels and that formulation of some questions was not clear and they were difficult to follow. It was discovered that the paper did not challenge the students enough in order to vividly show that they have grasped the content. The paper appeared rather simple for the mathematics educators who were the target group.

On analysing the marked scripts of the students it was discovered that students did not do well in question 1(d). The following issues were noticed:

- In some cases, a mark was given for getting half of the answer right and no mark was given for an incorrect example.

- A correct answer was given with no example.

- A definite incorrect answer was given but the example was accepted.

- A definite incorrect answer was given but the example was accepted although it showed mistakes.

- No definite answer was given but the example given was accepted as correct.

- Some learners did not attempt to answer the questions. The space was left blank.

Another issue that was noticed is that there was some inconsistency in the marking of the scripts. Another aspect is that it appeared as though the same memorandum was not used when marking the scripts, because in marking the scripts of Qwaqwa educators, it appeared as though harsh measures were not applied like in the case of the Odendaalsrus scripts. The preceding group therefore performed far better than their counterparts. This inconsistency leaves one wondering whether justice was done to the group that did not perform well as far as question 1 (d) in Figure 3 is concerned. Adler \& Reed (2000:210) ask what the performances of the students tell us about the learner, the teacher, 
the curriculum and the national standards. The response to this important question is addressed under discussion so as to give clarity and value to observed issues.

\section{Discussion}

Summative evaluation is important to assess if students do understand part or all the activities done during the course of learning. During the upgrading of educators, it is important that educators should have a sound knowledge of the learning area they are involved with. Their mastery of the learning content is crucial because they have to show a certain level of competence in the classroom situation.

The results under discussion (Figure 1) show that both groups obtained a percentage above 80\%, which might be attributed to the lower level cognitive domain type of questions asked. This is concord with Gowin's epistemological V theory that the left side of the brain (thinking activity) and the right side (doing activities) are used because the student has to use the abstract knowledge (Bloom) when required to. Educators need to transcend the lower levels of the cognitive domain so that high quality teaching and learning can be realized.

The results (Figures $1 \& 2$ ) indicate that students did readily understand the questions that seemed to be below their standard of mathematics literacy. The way they had been taught does answer the question whether the teaching and learning strategies used in the project does provide competent and knowledgeable teachers but the worrying factor is the validity of the marks given by the different facilitators (they are kilometers apart for them to discuss the method of marking the scripts) due to the fact that their marking is not giving the same results although reliability of the instrument used could be deemed to be guaranteed.

Fairbrother 2001:4) alludes that: "In its simplest term a reliable assessment will give similar results at different times and with different judges. Attempts to ensure that this happens can reduce the range of assessment methods and lead to conflict with validity. Their performance in all the questions is a clear indication that they have the ability to manipulate mathematical instructions given to them by their facilitators and they can go beyond the level of recalling and comprehension. Ramsuran (1999:102) in her research on Teachers' Experiences of Continuous Assessment, observed that quality of the task given were questionable because on closer analysis tasks that assessed recall and comprehension carried a relatively high weighting. It is the same with the finding of this study indicating that examiners need to go beyond the level of more comprehension by setting questions that would give educators the opportunity to show their mastery of mathematical concepts they gained or know. They should be given the elementary mathematics for the sake of regurgitation and at the end of the session, proclaim that they are competent mathematics educators. They are to be provided with opportunities to express themselves and show their mathematical skills by solving questions that are above the comprehension level of cognitive domain. They need to be fully empowered and encouraged to be critical thinkers. They can analyse, synthesize, criticize, and appreciate some aspects of the learning content. As capable teachers they can be able to compete with other mathematical educators who are their rival competitors and they can be able to provide alternative strategies to solve problems, so, they should be inculcated with a "sense of personal ownership of mathematics" (Ernest 2001:12)

It is important to have a thorough knowledge of the content and assessment skills when preparing formative and summative question paper. Care should be taken before an examination paper could be set, bearing in mind what the assessment policy say about the assessment standards and getting the right people who are more competent to do the job. What could be deduced as far as the setting of the exam paper not all of Bloom's cognitive domain levels were catered for, i.e., analysis, synthesis and evaluation were omitted. It also important that the question paper covers all the aspects of the learning content presented in the classroom. Gultig and Stielau (2009) state that test demand a range of skills that require a learner to move beyond reproducing work previously done in class. The assessor should have a privilege of adopting a diagnostic and reflective approach that is based on the level of comprehensions in the examination. With regard to Gowin's V, questions should determine the learning efficiency of the student in terms of the concepts mastered.

During the marking of the scripts educators participating in the project where worried about the standard of the paper and the made comments to highlight their unhappiness. Some of their comments were:

Educator A: "Oh Boy! Is this the paper for a person doing ACE? This can be answered by a Grade 12 learner. This is really bad."

Educator D: "There are too many mistakes in the marking of the scripts. Was the memorandum used to mark them? I see obvious mistakes being committed." 
As the educators continued with the marking of the scripts it was evident that the participating groups where experiencing some discrepancies with the way in which obvious mistakes and omissions occurred.

\begin{abstract}
Educator B: "Just look at these questions. Marks are not allocated consistently, some questions are not marked the same. I can see some of the sections are allocated marks although they are incomplete."

Educator C: "This is wrong. We did not come here to waste our time. Some of us know what is meant by having to set a question paper. Injustice is committed here."
\end{abstract}

\title{
8. Conclusion and Recommendations
}

In conclusion, it is with no doubt that what Motheo District has being doing a great job with regard to the upgrading of teachers. The study was to evaluate the project of the department of education (DOE). Through the use of assessing the examination question papers that the facilitators set for the educators and interviews with the participants it was evident that the manner in which assessment was conducted did not conform to the principles of setting a question paper that is questions asked should not be too easy or too difficult. They should be real examination questions covering all the competences of the students.

Students doing ACE should be given an opportunity to compile a question paper using the theories they were taught in class. They should also be given a chance to analyse and question the way in which question papers are being set by external assessors so that they can understand how curriculum and assessment really work when they are implemented in schools. Lecturers should play mentorship role by making students aware of the pressure teachers meet with regard to school objectives which encourages them to compile lower order of questions instead of covering all the levels the taxonomy so that students could be able to identify a quality paper from others. The researcher further recommends that the study should be conducted in areas that focus on the instructional content and test content . Furthermore students should be thoroughly observed when involved in the marking of the scripts of the learners.

\section{References}

Adler J Reed Y 2000. Researching teacher's 'take-up' from a formal in-service professional development programme. Journal of Education: Kenton special issue (25): 192-226.

Aldridge, Fraser \& Sebela 2004

Carnoy \& Loeb 2002. Does external accountability affect student outcomes? A cross-state analysis. Educational Evaluation and Policy Analysis 24(4): 1.

Corey K E 1985. Qualitative planning methodology: an application to two cases in development planning. In Nel B F (Ed.). Focus on Quality: Selected proceedings of a Conference on Qualitative Research Methodology in Social Sciences. Durban: University of Durban-Westville.

Coughlan M Cronin P Ryan F 2007. Step-by-step guide to critiquing research. Part 1: quantitative research. British Journal of Nursing 16 (11): 658-663

Department of Education 1996. Outcomes-Based Education in South Africa: background information for Educators. Unpublished.

De Corte K 2000. New perspectives for research and practice mathematics education. Pythagoras 52: 33-46.

Ernest P 2000. Language in mathematics. Proceedings of the annual international conference organized by the Department of Science and Mathematics Education. Darussalam: University of Brunei. File://D99Clasmate/Ftm Files/22Noridah.htm.

Fairbrother R W 2001. Assessment and evaluation in Science and Mathematics Education: Innovation Approaches (Secondary Science). Proceedings of the annual international conference organized by the Department of Science and Mathematics Education. Darussalam: University of Brunei. File://D99Clasmate/Ftm Files/22Noridah.htm.

Goduka I N 1996. Reconstruction for affirmative unity and diversity. South African Journal for Higher Education 10(2): 67-73.

Gultig J, Stielau J eds 2009. Getting Practical about classroom-based teaching for the National Curriculum Statement $2^{\text {nd }}$ edition. Cape Town: Oxford University Press.

Hoadley U, Jansen J 2009. Curriculum: organizing knowledge for the classroom $2^{\text {nd }}$ edition. Cape Town: Oxford University Press.

Heck RH Crislip M 2001. Direct and indirect writing assessments: examining issues of equity and utility. Educational Evaluation and Policy Analysis.

Lemmer EM, Badenhorst DC 1996. Introduction to education for South African teachers. Kenwyn: Juta.

Mills J B Mathew, Huberman AM 1984. Qualitative data analysis: a source book of new methods. Beverley Hills: Sage.

Novak J D 1980. Methodological issues in investigating meaningful learning. In: Archenhold W F, Driver RH Wood-Robinson C (Eds.): Cognitive Development Science and Mathematics. Leeds: University of Leeds.

Ramsuran A 1996. Teachers' experiences of Continuous Assessment: between Policy and Practice. Perspectives in Education 18(1): 99-110 